\title{
Play, art, music and exercise therapy impact on children with diabetes
}

\author{
loana Patricia Bacus ${ }^{1}$ [D $\cdot$ Husnain Mahomed ${ }^{2} \cdot$ Anne-Marie Murphy $^{1,2} \cdot$ Muiriosa Connolly $^{1,2} \cdot$ Orla Neylon $^{1,2}$. \\ Clodagh O'Gorman ${ }^{1,2}$
}

Received: 31 May 2021 / Accepted: 7 December 2021 / Published online: 17 January 2022

(c) The Author(s) 2022

\begin{abstract}
Diabetes mellitus (DM) is a global public health issue. Type 1 diabetes (T1D) is the predominant diabetes type in children and always requires insulin therapy. The incidence rate of newly diagnosed T1D in children continues to increase in Ireland Roche et al. (Eur J Pediatr 175(12):1913-1919, 2016) and worldwide Patterson et al. (Diabetologia 62(3):408-417, 2019). The objective of this study was to conduct a literature review of the effects of various non-pharmacological therapeutic modalities on the control of diabetes in children. A literature review was performed using PubMed, Medline, Embase and Cochrane library to evaluate play, art, music and exercise therapy in the treatment of DM using the keywords: "paediatric", "diabetes", "play therapy", "art therapy", "music therapy" and "exercise therapy”. These search terms initially returned 270 cases, which resulted in a total of 11 papers being reviewed after eliminating duplicate or irrelevant papers. Literature review showed that all therapies have a positive impact on the child, but there is limited research looking at the impact of therapy on quantitative measures such as HbAlc or 'time in range'.
\end{abstract}

Keywords Art therapy $\cdot$ Exercise therapy $\cdot$ Music therapy $\cdot$ Play therapy $\cdot$ Type 1 diabetes mellitus

\section{Introduction}

The incidence of diabetes mellitus (DM) continues to rise worldwide and modelling suggests that this increase will continue, according to the World Health Organization (WHO) (https://www.who.int/) and Centers for Disease Control and Prevention (CDC) (https://www.cdc.gov/). Among youth in the USA, both type 1 diabetes (T1D) and type 2 Diabetes (T2D) are increasing rapidly. Between 2000 and 2009, the incidence of T1D among children increased by $21 \%$ (from 1.48 to 1.93 per 1000 children), while T2D increased by $30 \%$ (from 0.34 to 0.46 per 1000 children) during the same timeframe [3]. Furthermore, the associated health care costs for youth with DM are on average six times higher than for youth without DM [4]. While T1D is the most common in all children and young people, the incidence of T2D among teens is increasing significantly in

Ioana Patricia Bacus

bacus.patricia@gmail.com

1 Department of Paediatrics, School of Medicine, University of Limerick, Limerick, Ireland

2 Department of Paediatrics, University of Limerick, Limerick, Ireland teenagers [5]. Regardless of type, DM is a chronic condition with a requirement for lifelong management and can pose many challenges. Teenagers face unique challenges and developmental changes that can make self-management of DM difficult. They experience social, cognitive, and psychological pressures that can impact their chronic disease management. These challenges include peer pressure, fear of social stigma, risk-taking behaviours and the drive for independence from parents. Given the trend of reduced adherence and suboptimal glycaemic control that typically occurs during adolescence, clinicians and researchers must continue to find ways to effectively reach teenagers and encourage good diabetes management habits [6].

Play is normal behaviour for children, and play therapy specifically has been found to be an effective care strategy for chronically ill children. Play accomplishes many goals for children beyond simple pleasure, including the means to evolve and prepare themselves for adulthood. Play is an important part of the learning process, and psychologists and educationalists are quick to highlight the value of play in the development of children. When children play they explore their abilities and learn to adapt and work within their environment. Play is also a key part of children's development regarding maturation of communication skills and understanding of their own bodies [7]. 
In art therapy there have recently been many qualitative studies that have focused on DM and its related issues [8, 9]. Although it is difficult to quantify the possible impacts on glycaemic control, the meaning that patients apply to an illness does affect how they rate their overall health [10]. Additionally, these perceptions may influence treatment effectiveness, psychological symptoms, coping and outcomes [10]. Arts are increasingly being utilized in health care and their use in psychotherapeutic contexts has been extensively studied previously, assisting patients to communicate their feelings more effectively. Camic discusses extensively how and why these approaches are useful from the view of health psychology, and Lane et al. discusses how these approaches have been actively used in nursing practice $[11,12]$. Stuckey and Nobel reviewed literature that looked into the relationship between creative arts and health outcomes, specifically in music engagement, visual arts therapy and creative expression and writing [13]. In all of these areas, they discovered clear indicators that engagement in artistic activities has significant positive impacts.

Music therapy has been shown to be beneficial for the health of children in a variety of contexts ranging from neonatal care to autism spectrum disorder [14]. Music therapy has been used to help with non-verbal processing of information and emotions [14]. Additionally it has been shown to positively impact the patients' mood and motivation leading to increased upper extremity function in neurorehabilitation [15]. Patients do not have to be musically gifted to be able to see an improvement in using music therapy [14].

Exercise therapy can affect endothelial function and in turn reduce the cardiovascular risk profile.

Regular physical activity has been shown to correct endothelial dysfunction in patients with chronic heart failure, hypercholesterolemia and polymetabolic syndrome [16]. A recent cross-sectional study indicated a strong correlation between the level of physical activity and vascular function in children with T1D [16].

\section{Methods}

A literature search was conducted for randomized control trials using PubMed, Medline, Embase and Cochrane library. In particular, articles containing the medical subject headings (MeSH) type 1 diabetes mellitus, art therapy, play therapy, dance therapy and music therapy were retrieved. The inclusion criteria utilized incorporated studies published till January 2020. Using the search terms "play therapy", "art therapy" "music therapy", "exercise therapy" and "diabetes" limiting it to people under the age of 18, 270 papers were identified of which 38 were excluded for being duplicates and 11 were selected for inclusion (Fig. 1). Play therapy had the most published articles with 4 papers identified, followed by art therapy and music therapy with 3 papers each and music therapy with 1 . Articles were selected on the basis that one of the four therapy modalities were used in children with diabetes to evaluate understanding of diabetes and/or improvement in glycaemic control. Papers were excluded if less than $50 \%$ of the participants were children. Feasibility studies were also excluded. Only English language papers were included.

\section{Results}

\section{Play therapy (4 papers)}

Henkemans et al. studied the use of technology in health education for children with T1D. Their study used a personal robot to quiz the children on educational questions relating to treatment of their diabetes. They found that the children were more responsive and engaged to education through the robot and perceived more enjoyment through the process. Although this level of enjoyment fell over time, it remained high compared to normal methods.

Pelicand et al. studied the impact of a therapeutic education program for children with diabetes. Over the course of 3 weeks during a summer camp, an educational program was implemented that was intended to both entertain the children

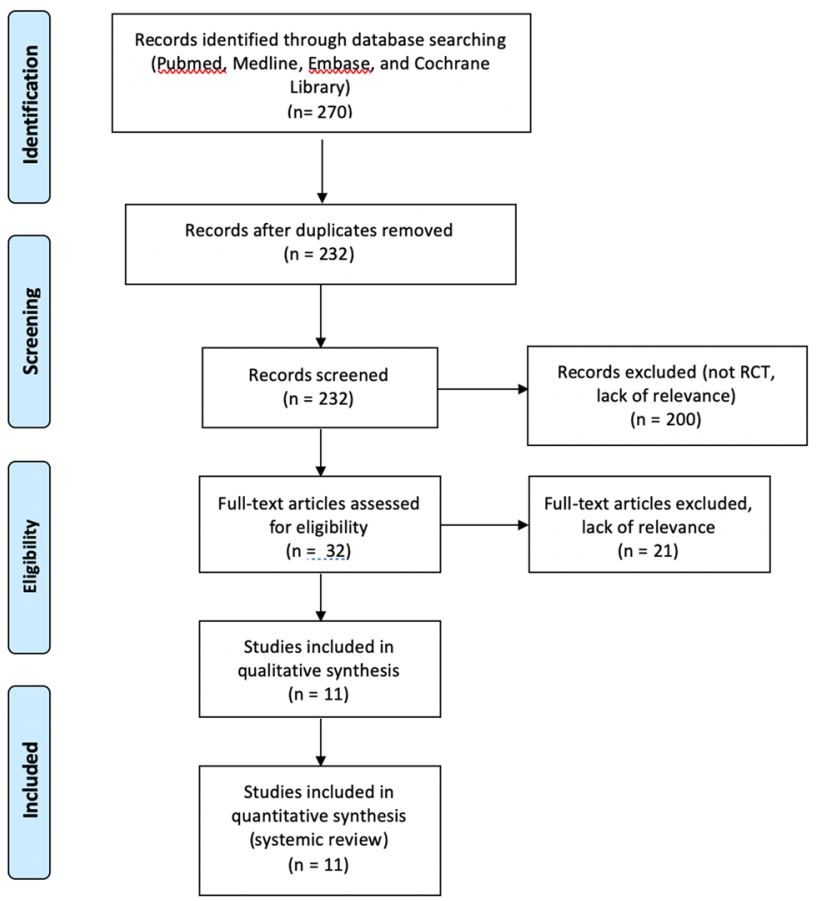

Fig. 1 Methods of systematic review of literature. Using search terms "Play therapy", "art therapy", "music therapy", "exercise therapy" and "diabetes" until January 2020. Limited to RCTs in paediatric population with T1DM 
while educating them on diabetes and treatment options to promote independence and health. The program was split into 7 workshops, lasting $1 \mathrm{~h}$ each. The results suggested that the children better understood the material compared to normal methods, and the program was perceived as good or very good by 13 out of the 14 children on a 5-point scale (very bad, bad, neutral, good, very good).

Pennafort et al. analysed the impact of using toys to help children with diabetes better understand glycaemic monitoring and insulin application. They had children perform these actions directly on dolls to help familiarize them with the procedures and improve their attitude towards them. They found that these actions helped to improve the ability of the children to independently perform these actions, becoming less afraid of needles and better understanding the need for insulin management.

La Banca et al. looked at instructional therapeutic play (ITP) as a method to help children better understand and master insulin therapy (Table 1). They found that ITP was an effective method to identify educational needs and associated care in school-aged children.

\section{Art therapy ( 3 papers)}

Vanelli et al. studied the use of drawing to help develop the understanding of diabetes and its treatments in young diabetes patients. They found that children who were better able to draw "The human body as it is inside" would have a stronger understanding of their type 1 diabetes and the associated treatments.

Macdonald et al. studied the use of art therapy to help support young adults transitioning from paediatric services to adult diabetes care (Table 2). They looked to measure diabetes-related emotional distress and determined that art therapy was helpful in reducing that stress in 57\% of the participants through a participant satisfaction evaluation form. Although their results were promising, they were limited by inconsistent attendance of sessions and a small sample size.

Harel et al. studied the impact of intensive art therapy in youth with poorly controlled type 1 diabetes. They used art therapy as an intervention to help assist with behavioural difficulties, including needle phobia and lack of compliance with nutritional requirements. They found that improvement in disease management was achieved in 56\% of the case group compared to $23 \%$ of the control group (29).

\section{Music therapy (1 papers)}

Gelernter et al. studied the use of auditory guided imagery (AGI) on glucose levels, glycated haemoglobin and quality of life in children with diabetes. Their study compared the effects of AGI with music vs. background music only (Table 3). The study consisted of 13 patients between

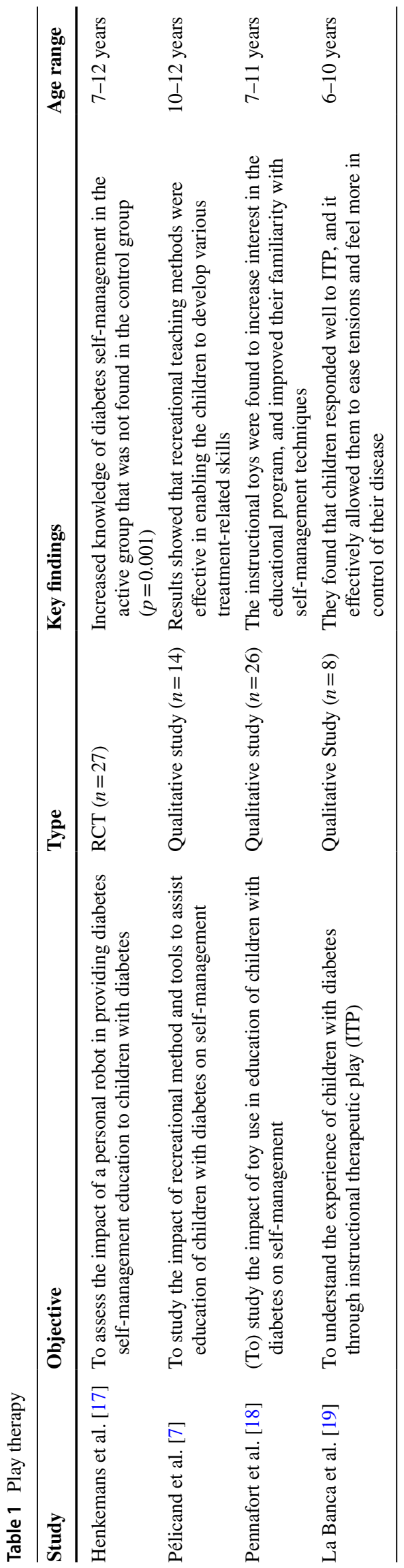


Table 2 Art therapy

\begin{tabular}{|c|c|c|c|c|}
\hline Study & Objective & Type & Key findings & Age range \\
\hline Vanellli et al. [20] & $\begin{array}{l}\text { To study the effectiveness of drawing } \\
\text { to test knowledge of diabetes in } \\
\text { children with diabetes }\end{array}$ & Qualitative study $(n=68)$ & $\begin{array}{l}\text { Drawing was an effective method to } \\
\text { test children on their understanding } \\
\text { of diabetes and related self- } \\
\text { management techniques }\end{array}$ & $5-14$ years \\
\hline Macdonald et al. [21] & $\begin{array}{l}\text { To study the use of art therapy to } \\
\text { assist in the transition of youth } \\
\text { from paediatric to adult diabetic } \\
\text { care }\end{array}$ & Qualitative study $(n=12)$ & $\begin{array}{l}\text { Art therapy was helpful in reducing } \\
\text { emotional stress }\end{array}$ & $15-25$ years \\
\hline Harel et al. [22] & $\begin{array}{l}\text { To evaluate the effect of art therapy } \\
\text { in youth with poorly controlled } \\
\text { type } 1 \text { diabetes }\end{array}$ & Retrospective report $(n=29)$ & $\begin{array}{l}\text { Art therapy was found to improve } \\
\text { disease management through } \\
\text { improved compliance }\end{array}$ & $6-14$ years \\
\hline
\end{tabular}

the ages of 7 and 16. They found that in both cases mean interstitial glucose concentration decreased, and $\mathrm{HbA} 1 \mathrm{c}$ decreased in both groups, but more significantly in the AGI group $(p=0.04)$.

\section{Exercise therapy ( 3 papers)}

Cafazzo et al. examined the use of a mobile health (mHealth) app to promote improved treatment adherence in young diabetes patients. Their app promoted rewards based on strong diagnostic readings, and they found that this incentivized improved behaviour and treatment adherence from the participants.

Lee et al. examined the impact of different types of exercise on insulin sensitivity and reducing total adiposity and ectopic fat in adolescents (Table 4). They compared aerobic and resistance exercise against each exercise type individually through a 6-month exercise routine (3 days a week, $180 \mathrm{~min}$ ). Eighty-five participants completed the study, with $90 \%$ exercise attendance. They found that the combined exercise program was similarly beneficial compared to the separate programs for improving insulin sensitivity and reducing ectopic fat.

Seeger et al. studied the impact of exercise on physical fitness and vascular function in children with diabetes. They used an 18-week program, and examined maximal oxygen consumption, brachial artery endothelial function, common carotid artery diameter, wall thickness and wall-to-lumen ratio. After the program, they found that maximal oxygen consumption improved $(p=0.039)$ and brachial artery endothelial function also improved $(p=0.038)$. Carotid artery diameter, wall thickness and wall-to-lumen ratio did not change with any significance $(p=0.26,0.53$ and 0.27 , respectively).

\section{Discussion}

In children with T1D, the literature supports the role of play therapy. Play therapy was used for education of patients with diabetes and showed that the patients tended to have a greater enjoyment of education. Children were more engaged in the play activities compared to the control; however, engagement did tend to fall over time. Pennafort et al. explored in more depth the effects of play therapy on children with DM by looking at children interacting with dolls and diabetic equipment. They found that doing so allows children to eliminate their doubts, explore their curiosities and alleviate fears associated with diabetes-related treatments.

Several studies identified positive impacts of art therapy in children diagnosed with T1D. The positive effects of art therapy include the reduction of stress in children, the provision of education and improving overall well-being. In high risk youth with diabetes and impaired glycaemic control, Harel et al. identified that art therapy can assist youth in expressing emotions without having to do it in words. By allowing children to use their imagination around various diabetes equipment they were able to create a new perspective and, therefore, increase adherence.

Table 3 Music therapy

\begin{tabular}{llll}
\hline Study & Objective & Type & Key findings \\
\hline Gelernter et al. [23] & $\begin{array}{l}\text { To study the effect of auditory guided imagery } \\
\text { (AGI) in addition to a standard diabetes care } \\
\text { program for youth }\end{array}$ & RCT $(n=13)$ & $\begin{array}{l}\text { Listening to AGI has potential in improving } \\
\text { glycaemic control and glucose levels in } \\
\text { youth with T1DM }\end{array}$ \\
\hline
\end{tabular}


There was no direct research on music therapy in the paediatric population with diabetes. Gelerneter et al. showed that glycaemic control improved in their study. This study could be used to help pave the path further for research on the impact of music therapy. Therapies such as art, music and play therapy are process orientated in nature, and the benefits can be difficult to measure by quantitative means. With advancing technology and increased abilities to measure throughout the therapy process, these challenges may potentially be reduced or eliminated, allowing these therapies to be better measured against conventional diabetes treatment strategies.

This study was meant to focus exclusively on children with only diabetes and controlling for play, exercise, art and music therapy. A limitation of this study is that children with diabetes can be included in a multitude of other studies alongside children with other chronic diseases thus potentially broadening the impact that different therapy modalities can have.

\section{Conclusion}

This paper summarizes the current literature of four different therapy modalities in children with T1D. At present, the research is most limited in regard to music therapy with the focus being on chronic diseases in adult population. A need for randomized controlled trials exists for looking at the four various therapies the effects of them on children with T1D. While various studies have been done and showed a positive effect on stress, understanding and engagement using play, art, music and exercise therapy, more needs to be done to look at the quantitative impact of them. Future directions of research could look at the impact of therapies on quantitative metrics of glycaemic control in children, such as the impact of play therapy on $\mathrm{HbA} 1 \mathrm{c}$ or 'time in range' in participants given the increasing prevalence and availability of continuous glucose monitoring.

Funding Open Access funding provided by the IReL Consortium.

\section{Declarations}

Conflict of Interest The authors declare no competing interests.

Open Access This article is licensed under a Creative Commons Attribution 4.0 International License, which permits use, sharing, adaptation, distribution and reproduction in any medium or format, as long as you give appropriate credit to the original author(s) and the source, provide a link to the Creative Commons licence, and indicate if changes were made. The images or other third party material in this article are included in the article's Creative Commons licence, unless indicated 
otherwise in a credit line to the material. If material is not included in the article's Creative Commons licence and your intended use is not permitted by statutory regulation or exceeds the permitted use, you will need to obtain permission directly from the copyright holder. To view a copy of this licence, visit http://creativecommons.org/licenses/by/4.0/.

\section{References}

1. Roche EF, McKenna AM, Ryder KJ et al (2016) Is the incidence of type 1 diabetes in children and adolescents stabilising? The first 6 years of a National Register. Eur J Pediatr 175(12):1913-1919. https://doi.org/10.1007/s00431-016-2787-6

2. Patterson CC, Harjutsalo V, Rosenbauer J et al (2019) Trends and cyclical variation in the incidence of childhood type 1 diabetes in 26 European centres in the 25 year period 1989-2013: a multicentre prospective registration study. Diabetologia 62(3):408-417. https://doi.org/10.1007/s00125-018-4763-3

3. Dabelea D, Mayer-Davis EJ, Saydah S et al (2014) Prevalence of type 1 and type 2 diabetes among children and adolescents from 2001 to 2009. JAMA 311(17):1778-1786. https://doi.org/10.1001/ jama.2014.3201

4. Shrestha S, Zhang P, Albright A, Imperatore G (2011) Medical expenditures associated with diabetes among privately insured U.S. youth in 2007. Diabetes Care 34(5):1097-101

5. Alberti G, Zimmet P, Shaw J et al (2004) Type 2 diabetes in the young: the evolving epidemic. Diabetes Care 27(7):1798-1811

6. Greening L, Stoppelbein L, Reeves CB (2006) A model for promoting adolescents' adherence to treatment for type I diabetes mellitus. Child Health Care 35(3):247-267

7. Pélicand J, Gagnayre R, Sandrin-Berthon B, Aujoulat I (2006) A therapeutic education programme for diabetic children: recreational, creative methods, and use of puppets. Patient Educ Couns 60(2):152-163. https://doi.org/10.1016/j.pec.2004.12.007

8. Stuckey HL, Tisdell EJ (2010) The role of creative expression in diabetes: an exploration into the meaning-making process. Qual Health Res 20:42e56

9. Zoffmann V, Kirkevold M (2007) Relationships and their potential for change developed in difficult type 1 diabetes. Qual Health Res $17: 625 \mathrm{e} 38$

10. McFarland KF, Rhoades DR, Campbell J, Finch WH (2001) Meaning of illness and health outcomes in type 1 diabetes. Endocr Pract 7:250e5

11. Camic PM (2008) Playing in the mud: health psychology, the arts and creative approaches to health care. J Health Psychol 13:287e98

12. Lane JT, Ferguson A, Hall J et al (2007) Glycemic control over 3 years in a young adult clinic for patients with type 1 diabetes. Diabetes Res Clin Pract 78:385e91

13. Stuckey HL, Nobel J (2010) The connection between art, healing, and public health: A review of current literature. Am J Public Health 100:254e63

14. Stegemann T, Geretsegger M, Phan Quoc E et al (2019) Music therapy and other music-based interventions in pediatric health care: an overview. Medicines (Basel, Switzerland) 6(1):25. https:// doi-org.proxy.lib.ul.ie/10.3390/medicines6010025
15. Magee WL, Clark I, Tamplin J, Bradt J (2017) Music interventions for acquired brain injury. Cochrane Database Syst Rev. https://doi. org/10.1002/14651858.CD006787.pub3

16. Fuchsjäger-Mayrl G, Pleiner J, Wiesinger GF et al (2002) Exercise training improves vascular endothelial function in patients with type 1 diabetes. Diabetes Care 25(10):1795-1801. https://doi.org/ 10.2337/diacare.25.10.1795. PMID: 12351480

17. Henkemans OAB, Bierman BPB, Janssen J et al (2017) Design and evaluation of a personal robot playing a self-management education game with children with diabetes type 1. Int J Hum Comput Stud 106:63-76. ISSN 1071-5819. https://doi.org/10.1016/j.ijhcs. 2017.06.001

18. Pennafort VPDS, Queiroz MVO, Gomes ILV, Rocha MFF (2018) Instructional therapeutic toy in the culture care of the child with diabetes type 1. Rev Bras Enferm 71(suppl 3):1334-1342. English, Portuguese. https://doi.org/10.1590/0034-7167-2017-0260. PMID: 29972532

19. La Banca R, Monteiro O, Ribeiro C, Borba R (2015) School experience of children with diabetes mellitus expressed by dramatic therapeutic play. 1981-8963. 9. 9009-9017. https://doi.org/10. 5205/reuol.8074-70954-1-SM0907supl201510

20. Vanelli M, Munari A, Fabbri D et al (2018) Could infantile interactive drawing technique be useful to promote the communication between children with type- 1 diabetes and pediatric team? Acta Biomed 89(2):233-241. https://doi.org/10.23750/abm.v89i2.7172. PMID:29957757;PMCID:PMC6179024

21. MacDonald C, Friedman S, Marks SD (2019) Creative arts diabetes initiative: group art therapy and peer support for youth and young adults transitioning from pediatric to adult diabetes care in Manitoba. Canada Can J Diabetes 43(6):377-383.e3. https:// doi.org/10.1016/j.jcjd.2019.04.016. Epub 2019 May 9. PMID: 31235397

22. Harel S, Yanai L, Brooks R et al (2013) The contribution of art therapy in poorly controlled youth with type 1 diabetes mellitus. J Pediatr Endocrinol Metab 26(7-8):669-673. https://doi.org/10. 1515/jpem-2012-0342. PMID: 23612534

23. Gelernter R, Lavi G, Yanai L et al (2016) Effect of auditory guided imagery on glucose levels and on glycemic control in children with type 1 diabetes mellitus. J Pediatr Endocrinol Metab 29(2):139-144. https://doi.org/10.1515/jpem-2015-0150. PMID: 26352084

24. Cafazzo JA, Casselman M, Hamming N et al (2012) Design of an mHealth app for the self-management of adolescent type 1 diabetes: a pilot study J Med Internet Res 14(3):e70. https://doi. org/10.2196/jmir.2058

25. Lee S, Libman I, Hughan K et al (2019) Effects of exercise modality on insulin resistance and ectopic fat in adolescents with overweight and obesity: a randomized clinical trial. J Pediatr 206:9198.e1. https://doi.org/10.1016/j.jpeds.2018.10.059. Epub 2018 Dec 13. PMID: 30554789; PMCID: PMC7193538

26. Seeger JP, Thijssen DH, Noordam K et al (2011) Exercise training improves physical fitness and vascular function in children with type 1 diabetes. Diabetes Obes Metab 13(4):382-4. https://doi. org/10.1111/j.1463-1326.2011.01361.x. PMID: 21226819

Publisher's Note Springer Nature remains neutral with regard to jurisdictional claims in published maps and institutional affiliations. 